\title{
ESTRATÉGIA DE FORMAÇÃO DE PREÇO DE VENDA/SERVIÇO DOS EMPREENDEDORES INCUBADOS NA RECEPETI
}

\author{
D. RIZZI ${ }^{1}$, A. ZANIN ${ }^{2}$
Programa de Pós-Graduação em Contabilidade e Controladoria - UFSC, ${ }^{2}$ Programa de Pós-graduação em Ciências
Contábeis e Administração - UNOCHAPECÓ
zanin@unochapeco.edu.br
}

Submetido 25/10/2016 - Aceito 19/02/2018

DOI: $10.15628 /$ holos.2018.5262

\section{RESUMO}

O artigo pretendeu responder a questão de estudo relacionada aos principais fatores associados para a formação do preço de venda/serviço dos empreendedores incubados na RECEPETI (Rede Catarinense de Inovação). Nessa direção, o objetivo principal do trabalho foi identificar os fatores associados para a formação do preço de venda/serviço dos empreendedores incubados vinculados a RECEPETI. Os procedimentos metodológicos utilizados para a realização desta pesquisa foram, quanto ao objetivo descritivo e, quanto à abordagem do problema é qualitativa. Quanto aos resultados do estudo, conclui-se que os principais fatores que a maioria das empresas alocam no preço final de seus produtos são: margem de lucro, mão-de-obra, aluguel/taxa de incubação, custo dos produtos/ matéria-prima, relação do preço do concorrente, tributação, gastos com suporte, servidor. Em casos de atualização do preço de venda, os principais fatores associados na atualização dos preços de venda estão lidados ao cenário econômico e o aumento do custo e despesas das atividades ligadas ao produto final, entre outros achados mencionados no decorrer desta pesquisa.

PALAVRAS-CHAVE: Preço de Venda, Incubadora, Custo.

\section{SELLING PRICE OF TRAINING STRATEGY / SERVICE OF THE ENTREPRENEURS INCUBATED RECEPETI}

\begin{abstract}
The article aims to answer the question of study related to the main factors related to the formation of sales / service of entrepreneurs incubated in RECEPETI (Santa Catarina Network Innovation). In this direction, the main objective was to identify factors associated with the formation of the sales / service of the incubated entrepreneurs linked to RECEPETI. The methodological procedures used for this research were when the descriptive purpose, as the case study of research procedures and, as the problem of the approach is qualitative. As for the results of the study, it is
\end{abstract}

concluded that the main factors that most allocate companies in the final price of their products are: profit margin, hand lab or, rent / hatching rate, cost of goods / raw material, price ratio competitor, taxation, spending on support, server. In case of update of the sales price, the main factors associated to update the sales prices are handled the economic scenario and increasing the costs and expenses of the activities related to the final product, among other findings mentioned during this study.

KEYWORDS: Selling Price, Incubator, Cost. 


\section{INTRODUÇÃO}

O atual cenário econômico é marcado pela acirrada concorrência. Desta forma as empresas precisam cada vez mais buscar novas formas de executar suas atividades e de gerenciar seus recursos, com o objetivo de reduzir os custos, aumentar a produtividade e, ao mesmo tempo, atender as exigências de seus clientes.

Uma das principais funções da gerência de qualquer negócio é a tomada de decisões, sendo que as mesmas direcionam as empresas e em consequência determinam os seus resultados. Estabelecer preço para produtos e serviços é uma decisão responsável por muito mais do que a simples definição de um valor monetário a um produto ou serviço. São os preços que auxiliam a imagem de uma marca - seja ela de qualidade superior ou de um produto de valor por dinheiro. Também são as decisões dos preços efetivamente praticados que determinam níveis de lucratividade em qualquer negócio (Zornig, 2007), ponderando, assim, a necessidade da ciência do gestor no negócio para a tomada de decisões.

A base de toda gestão econômica da empresa é o perfeito conhecimento dos custos, sem o que não há gestão econômica coerente. A composição do custo e o conhecimento dos fatores que influenciam no mesmo são a pedra fundamental na qual repousa todo o resto (Sartori, 2004).

Dentro da gestão dos custos, a formação de preço de venda emerge como o segundo principal objetivo após a apuração do custo unitário dos produtos e serviços. Os alicerces da formação e gestão de preços de venda decorrem da decisão de investimentos e dos elementos formadores da rentabilidade, o retorno do investimento. Assim, pode ser considerado que a determinação do preço de venda é a variável operacional mais importante da gestão empresarial (Padoveze \& Vasconcelos, 2012).

A gestão de decisão de valores atribuídos aos produtos e serviços oferecidos é uma realidade aplicável também às empresas sediadas em incubadoras empresariais. Segundo Dornelas (2002), a atual estrutura das incubadoras vem sendo aprimorada desde a década de 1970, quando nos Estados Unidos e na Europa Ocidental, as universidades, governos locais e instituições financeiras se reuniram para promover o processo de industrialização de regiões em declínio ou pouco desenvolvidas. Nesse sentido, esse tipo de organização tende a contribuir positivamente no processo de maturação de negócios iniciantes, inclusive com a possibilidade de ofertar orientações acerca de controles internos cabíveis para aprimorar a gestão dos novos empreendimentos. Contudo, a adoção de controles depende das políticas adotadas pelos empreendedores e vincula-se a diversos aspectos, inclusive de ordem subjetiva (como a facilidade de compreensão e utilidade dos mesmos no atual ciclo de vida da entidade).

Destarte, neste estudo se pretendeu indagar a respeito de quais os principais fatores associados para a formação do preço de venda/serviço dos empreendedores incubados na RECEPETI (Rede Catarinense de Inovação)?

Referida questão de pesquisa está relacionada às seguintes hipóteses:

$\mathrm{H} 1$ : Os gestores desse tipo/porte de empreendimento priorizam exclusivamente o controle dos aspectos operacionais para a formação do preço de venda. 
H2: Tende a englobar todos os referidos custos decorrentes para a constituição do preço final dos produtos/serviços ofertados.

Assim, para dirimir as dúvidas suscitadas a pesquisa teve como objetivo identificar os fatores associados para a formação do preço de venda/serviço dos empreendedores incubados vinculados a RECEPETI.

É pertinente destacar que estudos com esse tipo de abordagem se justificam porque no Brasil estão em funcionamento mais de 380 incubadoras (ANPROTEC, 2011), que contribuem para a criação e fortalecimento de empresas, tanto do ponto de vista operacional como gerencial. Nesse sentido, a partir do diagnóstico realizado, talvez seja possível identificar eventuais necessidades de aprimoramento das políticas adotadas pela direção da incubadora, com a intenção de melhorar as condições para que as empresas incubadas possam se fortalecer e se desenvolverem adequadamente, mesmo após o período de vínculo com a instituição.

\section{REVISÃO BIBLIOGRÁFICA}

A revisão da literatura apresenta os conceitos que sustentam o assunto pesquisado e servem de base para análise dos dados coletados, como destacado nas próximas seções.

\subsection{Gestão de custos e formação de preço de venda}

As tendências do mercado atual evidenciam que o gerenciamento dos custos em uma organização é fundamental, principalmente para o controle efetivo da lucratividade da atividade executada. Este processo está atrelado aos procedimentos de formação do preço de venda final do produto/serviço. Segundo Bodnar e Hopwood (1990), um eficiente sistema de custos produz relatórios importantes para os gestores, que devem indicar os custos de produção, bem como a lucratividade que cada produto vem proporcionando.

Para um controle coerente das atividades executadas, o processo de gestão de custos deve estar alinhado aos objetivos da organização, assim atenderá a necessidade do produto/serviço e vai de encontro com as expectativas dos gestores. Conforme Callado, Miranda e Callado (2003), um sistema de custos bem organizado e apropriado aos objetivos da empresa, que seja preciso e atualizado, mostra à empresa o que está acontecendo, servindo de base para a administração tomar decisões sobre a forma de alocação dos recursos disponíveis, com o objetivo de maior otimização dos resultados.

A gestão de custos se caracteriza por ser um instrumental analítico de contabilidade gerencial. Nesta linha este importante sistema trabalha com análise da lucratividade dos produtos e serviços, ou seja, num detalhamento da demonstração dos resultados, objetivando identificar quais os produtos ou serviços, ou linhas de produtos ou serviços, contribuem mais ou menos para a geração dos resultados (Padoveze, 2012).

Neste cenário, um controle efetivo dos custos agregados no processo produtivo de um produto/serviço, possibilita ao gestor maior confiabilidade no momento da tomada de decisões. Além deste benefício, o controle de custos também proporciona ao gestor, segundo Callado, Miranda e Callado (2003), determinar o custo dos produtos como um dos critérios da fixação de preços; analisar a rentabilidade das diversas atividades e produtos da empresa; avaliar os 
estoques; determinar a estrutura de custos dos produtos e compará-la com a concorrência; bem como empregar os recursos onde produzam melhores resultados.

Atrelado ao processo de tomada de decisões, a gestão de custos exerce papel fundamental para a formação do preço dos produtos/serviços que serão vendidos ou comercializados. Segundo Padoveze (2012), os dados para a formação dos preços de venda devem estar dentro de uma perspectiva do futuro, calculados considerando a empresa em condições normais de operação e ocupando a sua capacidade de produção.

O processo de formação do preço de venda, além dos custos, também está entrelaçado às condições do mercado, ao nível de atividade e à remuneração do capital investido. Dessa forma, o cálculo do preço de venda deve chegar a um valor que permite trazer à empresa a maximização dos lucros, ser possível manter a qualidade, atender aos anseios do mercado àquele preço determinado e melhor aproveitar os níveis de produção (Bruni \& Famá, 2012).

Com base nos métodos existentes para o controle efetivo do custo e para formação do preço de venda dos produtos e serviços, apresentam-se os Quadros 1 e 2, com o propósito de fundamentar teoricamente cada modelo.

\section{Quadro 1 - Métodos de custeio}

\begin{tabular}{|c|c|}
\hline \multirow{4}{*}{ 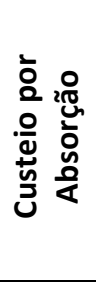 } & - Os custos indiretos são rateados entre os produtos, de acordo com critérios tradicionais; \\
\hline & - São adotados de acordo com as premissas gerenciais; \\
\hline & $\begin{array}{l}\text { - Para avaliação dos custos e cômputo de estoques, são: proporção dos custos diretos, proporção do } \\
\text { custo de MOD, quantidade produzida, tempo utilizado pelas máquinas, área de ocupação das máquinas, } \\
\text { custo da matéria-prima básica; }\end{array}$ \\
\hline & - Podem proporcionar dados inseguros a respeito de suas contribuições reais para a empresa. \\
\hline \multirow{5}{*}{ 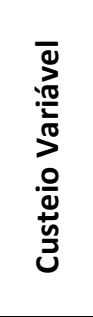 } & - Método para fins gerenciais, não utilizados fiscalmente; \\
\hline & $\begin{array}{l}\text { - Os custos indiretos não são levados à análise de resultados dos produtos, estes passam a ser avaliados } \\
\text { por suas margens de contribuição; }\end{array}$ \\
\hline & - A margem de contribuição é calculada pela diferença entre o preço de venda e os custos variáveis; \\
\hline & - Indica a lucratividade dos produtos e serviços; \\
\hline & - O método é excelente para averiguar o efeito de políticas de vendas especiais. \\
\hline \multirow{6}{*}{ 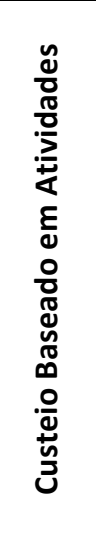 } & $\begin{array}{l}\text { - Proporciona estimativas mais realistas sobre como os custos de suporte mudam com incrementos no } \\
\text { volume de vendas; }\end{array}$ \\
\hline & $\begin{array}{l}\text { - Permite às empresas estimar não apenas os custos de fabricação, mas também os custos para servir } \\
\text { diferentes consumidores; }\end{array}$ \\
\hline & $\begin{array}{l}\text { - A lógica deste método é voltada para o custeio das atividades que geraram os custos e despesas e para } \\
\text { os motivos principais de suas gerações; }\end{array}$ \\
\hline & $\begin{array}{l}\text { - Estabelecem relações entre as atividades e o consumo de recursos, independentemente de fronteiras } \\
\text { departamentais; }\end{array}$ \\
\hline & - Originária do segmento industrial, porém é aplicável a organizações de serviços quanto à indústria; \\
\hline & $\begin{array}{l}\text { - Leva o custo incremental a categorias de custos que não são nem fixos e nem variáveis, mas são } \\
\text { semifixos, de acordo com o direcionador de atividades. }\end{array}$ \\
\hline
\end{tabular}




\begin{tabular}{|c|c|}
\hline \multirow{5}{*}{ 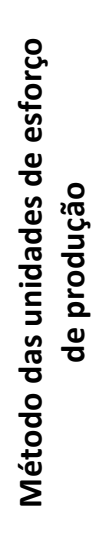 } & $\begin{array}{l}\text { - Modelo de cálculo da produção do período por meio da determinação de uma unidade de medida } \\
\text { comum a todos os produtos e processos da empresa; }\end{array}$ \\
\hline & $\begin{array}{l}\text { - Quaisquer que sejam as variações dos preços unitários, os esforços de produção desenvolvidos pelas } \\
\text { operações elementares de trabalho em uma fábrica são interligados entre si por relações constantes no } \\
\text { tempo; }\end{array}$ \\
\hline & - O valor de custo do estoque deve incluir todos os custos de aquisição e de transformação; \\
\hline & $\begin{array}{l}\text { Para implantação desse método de custeio é necessário percorrer as seguintes etapas: Divisão da } \\
\text { empresa em postos operativos; Cálculo dos potenciais de produção dos postos operativos; Definição de } \\
\text { um produto-base; Cálculo do foto-custo do produto-base; Cálculo dos potenciais produtos dos postos } \\
\text { operativos; Cálculo do valor dos produtos em UEPs; }\end{array}$ \\
\hline & $\begin{array}{l}\text { - O método UEP enfoca a transformação dos produtos, as despesas de estrutura não são abrangidas pelo } \\
\text { mesmo. }\end{array}$ \\
\hline \multirow{9}{*}{ 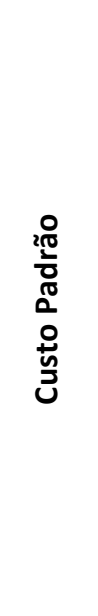 } & - A grande finalidade deste método é o controle dos custos; \\
\hline & $\begin{array}{l}\text { - Seu objetivo é o de fixar uma base de comparação entre o que ocorreu de custo e o que deveria ter } \\
\text { ocorrido; }\end{array}$ \\
\hline & $\begin{array}{l}\text { - O custo padrão não é um método meramente para contabilização de custos, mas sim uma técnica } \\
\text { auxiliar; }\end{array}$ \\
\hline & - Para ter sucesso na implementação a empresa tem que ter um bom custo real; \\
\hline & $\begin{array}{l}\text { - Este método não é um meio simplificado, custo padrão implica sempre na adoção de mais trabalho por } \\
\text { parte da empresa; }\end{array}$ \\
\hline & $\begin{array}{l}\text { - O sucesso deste método depende da seriedade aplicada na localização e saneamento das diferenças } \\
\text { entre o padrão e o real; }\end{array}$ \\
\hline & - Dividem-se em: \\
\hline & * Custo padrão corrente: exclui as ineficiências que a empresa julgar que podem ser de fato sanadas; \\
\hline & * Custo padrão ideal: só exclui o que não pode ser cientificamente eliminado. \\
\hline
\end{tabular}

Fonte: Adaptado de Assef (2005); Nagle \& Hogan (2007); Padoveze \& Vasconcelos (2012); Wernke \& Lembeck, (2012).

O Quadro 1 apresenta os principais métodos de custeio, sendo os mais recomendados o custeio baseado em atividade e o custo padrão, porém por ser uma ferramenta de gestão é cargo do administrador designar qual método será utilizado.

Sob a óptica da entidade, quanto maior o preço, maiores os lucros e melhores os resultados. Os limites superiores dos preços, porém, são definidos pelo mercado consumidor e pelo valor percebido e atribuído ao produto ou serviço comercializado. Assim, a análise de custos, preços e valores consiste em algumas das mais nobres e importante tarefa da administração financeira (Bruni \& Famá, 2012).

No Quadro 2 contextualiza-se os métodos de formação de preços de venda dos produtos/serviços:

Quadro 2: Métodos de formação de preço de venda

\begin{tabular}{|c|c|}
\hline \multirow{5}{*}{ 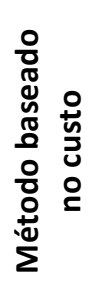 } & - É o mais comum na prática dos negócios; \\
\hline & $\begin{array}{l}\text { - Se for com base no custo total, a margem adicional deve ser suficiente para cobrir os lucros } \\
\text { desejados; }\end{array}$ \\
\hline & $\begin{array}{l}\text { - Se for com base no custo marginal, a margem adicional deve cobrir, além dos lucros, os custos } \\
\text { fixos; }\end{array}$ \\
\hline & - Este método é bastante utilizado em comércio atacadista e varejista; \\
\hline & - Este método é simples, mas pode levar a administração a tomar decisões equivocadas. \\
\hline
\end{tabular}




\begin{tabular}{|l|l|}
\hline \multirow{4}{*}{} & - Todos os métodos devem ser comparados com os preços das empresas concorrentes; \\
\cline { 2 - 3 } & - Este método é desdobrado em: \\
\cline { 2 - 3 } & * Método do preço concorrente: adotado nos casos de produtos vendidos a um mesmo preço \\
por todos os concorrentes;
\end{tabular}

Fonte: Santos (2012).

O Quadro 2 conceitua os principais métodos para a formação de preço de venda, e conforme descrito, o método mais coerente é o método misto, por estabelecer a combinação entre os custos envolvidos, as decisões de concorrência e as características do mercado.

As considerações financeiras internas e as considerações externas de mercado são, na maioria das empresas, forças antagônicas nas decisões de formação do preço de venda. Os gerentes financeiros alocam os custos para determinar quão altos os preços precisam ser para se atingirem os objetivos de lucro. As equipes de marketing e vendas analisam os consumidores para determinar quão baixos os preços precisam ser para se atingirem os objetivos de vendas. Desta forma a decisão eficaz sobre preços deve envolver uma combinação destes fatores, e não uma concessão entre restrições financeiras internas e condições externas de mercado (Nagle \& Hogan, 2007).

Um ponto impactante na gestão das empresas no processo de atualização do preço de venda é acompanhar a competitividade turbulenta, estimulada por um cenário tecnológico que acelera a velocidade da internacionalização da economia e a mudança de valores, exige das organizações a revisão das suas responsabilidades e estratégias, bem como encaminhamento de novas formas de ação externas e internas. Com isso aumenta ainda mais a responsabilidade do gestor na sua tomada de decisões (Teixeira \& Mazzon, 2000).

De fato, a busca pela eficácia operacional, a qual todas as atividades têm o retorno esperado, sendo que Porter (2002), analisa a estratégia de desempenhar atividades similares aos rivais de forma otimizada, capacitação para utilizar melhor os ativos da empresa. Ela é imprescindível para a obtenção do desempenho superior, mas não é o bastante para assegurar uma condição competitiva sustentável ao longo do tempo, pois rapidamente essas melhores práticas são imitadas. Como aspecto negativo, o autor destaca que a eficácia operacional leva as empresas a competir por preços baixos. 
São inúmeros os desafios que os gestores se deparam na formação de suas estratégias de gestão, sendo de grande responsabilidade a aplicação de um preço coerente para não comprometer as atividades da empresa, pois na maioria das instituições, a venda dos produtos estão ligadas ao fim monetário da empresa. Acertar a tomada de decisão desencadeia assim, o sucesso e permanência dos negócios.

\subsection{Incubadoras tecnológicas}

A incubação de empresas apresenta-se como um fenômeno mundial, surgido primeiramente em países desenvolvidos que identificaram nesta modalidade de apoio às empresas nascentes, um potencial desenvolvimentista, sobretudo, por meio de tecnologias traduzidas em processos inovadores. No Brasil as ações do governo têm caminhado timidamente em direção da promoção de um ambiente favorável ao desenvolvimento de incubadoras de empresas (D'Afonsêca, 2007). Conforme dados analisados pela ANPROTEC, em 2011 havia 384 (trezentos e oitenta e quatro) incubadoras em funcionamento no Brasil.

A atual estrutura das incubadoras vem sendo aprimorada desde a década de 1970, quando nos Estados Unidos e na Europa Ocidental, as universidades, governos locais e instituições financeiras se reuniram para promover o processo de industrialização de regiões em declínio ou pouco desenvolvidas. Neste sentido, esse tipo de organização tende a contribuir positivamente no processo de maturação de negócios iniciantes, inclusive com a possibilidade de ofertar orientações acerca de controles internos cabíveis para aprimorar a gestão dos novos empreendimentos (Dornelas, 2002).

No Brasil um dos principais órgãos reguladores das incubadoras tecnológicas é o Ministério de Ciência e Tecnologia e Inovação (MCTI), o qual define ações estratégicas voltadas para a promoção da inovação com objetivo de aumentar a competitividade e a inserção internacional das empresas brasileiras, sendo elas: incentivar a criação de novas empresas de base tecnológicas, especialmente por meio da incubação e do desenvolvimento de capital de risco; e apoiar a disseminação da cultura do empreendedorismo no sistema de ensino (Brasil, 2002).

Um dos pioneiros na implantação de incubadoras de empresas no Brasil é o Estado de Santa Catarina que vem integrando esforços para ampliar, de forma consciente e racional, o número de incubadoras nas diferentes regiões do estado e, ao mesmo tempo, contribuir para a consolidação daquelas que estão em funcionamento (RECEPETI, 2016).

As incubadoras de empresas, tipicamente, fornecem subsídios na fase de preparação dos novos empreendimentos, estrutura e ambiente de apoio e, ainda, favorecem a disseminação de uma cultura empreendedora - atributos que estimulam o desenvolvimento e crescimento de novos e pequenos negócios (Lalkaka, 2002). Esse tipo de organização facilita o processo de criação bem-sucedida de novas pequenas empresas, provendo-lhes uma compreensível e integrada diversidade de serviços, que incluem, entre outros elementos, espaço físico, serviços de consultoria e treinamento, financiamento, networking, assistência em projetos e capital de risco (Adegbite, 2001), elementos que guardam estreita harmonia com o que a literatura denomina capital intelectual.

Em outras palavras, os investimentos realizados pelas incubadoras de empresas direcionam-se, especialmente, ao aprimoramento no que Sveiby (1998) denomina capital 
humano, estrutural e de relacionamento das empresas incubadas, já que todas as ações das incubadoras a favor das empresas incubadas são direcionadas ao: (i) capital humano, pela capacitação dos gestores e das suas equipes de trabalho; (ii) capital estrutural, pela disponibilização de infraestrutura, física e de serviços, a baixo custo; e (iii) capital de relacionamento, pela disseminação de sua rede de relacionamentos - um dos postos-chaves para comunicação com o mercado-alvo, para a obtenção de novos clientes, assim como com os fornecedores, parceiros tecnológicos, bancos e órgãos financiadores.

Neste âmbito, as incubadoras são vistas como um ambiente flexível, encorajador e de facilitação para o surgimento, crescimento e desenvolvimento de novos empreendimentos ou de aperfeiçoamento dos já existentes, cujos resultados esperados deverão garantir, em prazo e tempo determinados, autonomia e auto sustentação das empresas (Aranha, 2000).

\subsection{Estudos correlatos}

Acerca de pesquisas com o mesmo foco desta (fatores utilizados na formação de preço de venda pelos incubados em incubadoras tecnológicas) não foram detectados em buscas realizadas nas plataformas de pesquisa on-line "Spell", "Scielo", "Periódicos Capes", "Science Direct" e "Scopus" no mês de fevereiro de 2016. Para efetivação destas foram utilizadas as palavras-chave "formação preço de venda" e "incubadoras", bem como os termos correlatos em inglês.

No entanto é pertinente mencionar as pesquisas a seguir, que mostram estudos com abordagem semelhante em um dos tópicos desta pesquisa.

Callado, Miranda e Callado (2003) fizeram uma pesquisa com objetivo de analisar a gestão de custos e o processo de formação de preços das agroindústrias paraibanas. A pesquisa envolveu um estudo empírico com 20 empresas do setor da agroindústria pertencentes a sete atividades distintas. Os dados foram obtidos através da aplicação de um questionário. Através do estudo pode ser analisado que a maioria das empresas possuía sistemas de custos ou alguma forma de estrutura de custos. Com o estudo foi possível constatar que o principal critério utilizado no processo de formação do preço de venda das empresas analisadas foi o Mark-up, aplicado sobre o custo de produção. Uma parcela das empresas pesquisadas utiliza o Mark-up sobre o valor da matéria-prima.

Na pesquisa de Braga, Braga e Souza (2009) o estudo foi desenvolvido com o objetivo de analisar as questões relacionadas à gestão dos estoques, do capital de giro, do processo de formação de preços, e da gestão de custos em indústrias conserveiros do estado do Rio Grande do Sul. A pesquisa, realizada no ano de 2008 , envolveu um estudo empírico com as oito empresas conserveiros do estado do Rio Grande do Sul cujo faturamento anual situa-se acima de R\$ 12 milhões. Os principais resultados do estudo com análise voltado ao atual artigo indicaram que: a maioria das empresas pesquisadas utiliza sistema de custos ou alguma forma de estrutura de custos, com tradicionais técnicas de mensuração e gestão dos custos do processo produtivo; o principal método utilizado na formação do preço de venda é o mark-up, aplicado sobre o custo total de produção; as correlações mais significativas e relevantes foram observadas entre os métodos de custeio utilizados e a adoção do conceito de margem de contribuição, assim como dos métodos de custeio com a técnica do ponto de equilíbrio; o estudo também identificou diversas inconsistências conceituais nas respostas dos gestores, revelando suas limitações de formação. 
O estudo de Souza et al. (2015) baseou-se em uma proposta de modelo de gestão aplicável às incubadoras, tendo por base os mapas estratégicos e painéis de desempenho à luz das premissas do Balanced Scorecard (BSC) e utilizá-lo como ferramenta de medição de desempenho das empresas incubadas de acordo com as práticas-chave do modelo CERNE. Os achados da pesquisa indicam uma proposta inicial de mapa e painel de desempenho contemplando as quatro perspectivas propostas pelo BSC.

\section{METODOLOGIA}

Este estudo, quanto aos objetivos, pode ser classificado como descritivo, pois de acordo com Gil (2008) as pesquisas descritivas almejam efetuar a descrição das características de uma população, fenômeno ou de uma experiência. Lopes (2006) destaca, ainda, que a pesquisa descritiva se preocupa em observar os fatos, registrá-los, analisá-los, classificá-los, interpretá-los e o pesquisador não interfere neles.

Quanto à abordagem, este estudo é classificado como sendo qualitativo, pois o seu objetivo está relacionado ao "levantamento de dados sobre as motivações de um grupo, em compreender e interpretar determinados comportamentos, a opinião e as expectativas dos indivíduos de uma população" (Turato, 2005, p. 509).

A coleta de dados aconteceu por meio da aplicação de questionário nos meses de janeiro a março de 2016, sendo utilizada as ferramentas do Googledocs. A população da pesquisa envolveu 291 empresas incubadas vinculadas a Rede RECEPET, sendo que 26 responderam e compuseram, assim, a amostra abrangida pelo estudo.

O questionário foi composto por 19 (dezenove) questões, sendo divididas em 15 (quinze) de múltiplas escolhas, 3 (três) em forma de escala e 1 (uma) questão aberta.

No que tange às etapas de processamento e análise dos dados, estes foram tabulados em planilha Excel, utilizando-se a estatística descritiva (média e desvio-padrão) pelo reduzido número de entidades abrangidas e de tabulações gráficas.

\section{RESULTADOS E DISCUSÃO}

Iniciada em 2001, a Rede Catarinense de Inovação (RECEPETI) é uma associação civil sem fins econômicos, com personalidade jurídica de direito privado, que atua para promover a educação, o desenvolvimento econômico, social, científico e tecnológico e o empreendedorismo inovador no Estado de Santa Catarina. Sua função é reunir entidades públicas e privadas com interesses comuns e proporcionar integração com incubadoras, parques tecnológicos, distritos de inovação, núcleos de inovação tecnológica e outros atores (RECEPETI, 2016).

A Rede RECEPETI tem como missão promover a educação, o desenvolvimento econômico, social, científico e tecnológico e o empreendedorismo inovador em Santa Catarina, estabelecendo parcerias e articulações com entidades públicas e privadas para alavancar a competitividade e a capacidade de desenvolvimento sustentável dos seus associados.

As incubadoras vinculas à rede são: $\mathrm{CITeB}$ Centro de Inovação e tecnologia de Biguaçu Universidade do Vale do Itajaí; CitiBrusque - Centro de Incubação, Tecnologia e Inovação de Brusque; Incubadora tecnológica da UNOCHAPECÓ (INCTECh); Pré-incubadora Oeste 
Incubadora tecnológica e Empresarial da Universidade do Contestado - Campus de Concórdia; Instituto Pró-Inovação do Sul Catarinense - iPROi; Incubadora Tecnológica de Ideias e Negócios ITEC.IN; CELTA - Centro Empresarial para Laboração de Tecnologias Avançadas; Midi tecnológico; Agência de Desenvolvimento Empresarial da Região de Ibirama (ADERI); UNIINOVA/ITE - Núcleo de Inovação Tecnológica - Incubadora Tecnológica Empresarial; Centro de Inovação e Pesquisas Tecnológicas - JaraguaTec; Pré Incubadora Tecnovale; Fundação Softville; Micro Distrito de Base tecnológica de Lages - Incubadora Midilages; Incubadora Tecnológica de Luzerna; Incubadora Tecnológica Mafratec; Instituto de Apoio à inovação e Tecnologia de palhoça - INAITEC; GTEC (Núcleo Gerador de Empresas de Desenvolvimento Integrado de Incubação); Incubadora Tecnológica de São Bento do Sul - ITFETEP; IESJ Incubadora de Empresas de São José Universidade do Vale do Itajaí - UNIVALI; Centro de Tecnologia do Planalto Norte - TECPLAN; Incubadora de Empresas da UNISUL e Instituto Gene Blumenau.

Para a análise e interpretação dos dados obtidos nesta pesquisa, considerou-se a seguinte sequência: análise do perfil das empresas envolvidas na amostra, identificação dos componentes utilizados na formação do preço de venda, levantamento dos custos apropriados e as dificuldades mencionadas pelos respondentes para a formação e aplicação dos custos de seus produtos/serviços ofertados.

O perfil da amostra coletada configura-se por empresas pertencentes ao setor de prestação de serviço $(91,66 \%)$, indústria $(4,17 \%)$ e comércio $(4,17 \%)$. Sendo as atividades de software/games $(70,83 \%)$, desenvolvimento de produtos (12,50\%), design (8,33\%), e-commerce $(4,17 \%)$ e automação residencial $(4,17 \%)$. Visualiza-se que há um número significativo de empresas que se configuram em prestadores de serviços ligados às atividades de software/games.

O tempo de existência das empresas é de menos de um ano, representando $37,50 \%$ dos entrevistados, $12,50 \%$ tem mais de um ano e menos de dois anos de funcionamento, $25,00 \%$ das empresas atuam a mais de dois anos e menos de cinco, e $25,00 \%$ tem mais de cinco anos de existência. A quantidade de funcionários nas empresas é de $37,50 \%$ com até três pessoas vinculadas, $12,50 \%$ com quatro a seis funcionários, $8,33 \%$ com funcionários entre sete e dez, e 40,67\% das empresas entrevistadas não tem funcionários vinculados às mesmas.

O produto ofertado tende a suprir as necessidades de seus públicos-alvo (clientes), os quais são direcionados conforme o fator-chave de cada mercadoria. São diversas as possibilidades de diferenciar-se no mercado, seja pela qualidade, por preços mais atrativos, produtos diferenciados ou por serviços incorporados nos produtos. No Gráfico 1, ilustra os fatores-chaves indicados pelos incubados que tendem a se posicionar no mercado.

Gráfico 1: Fator-chave das empresas

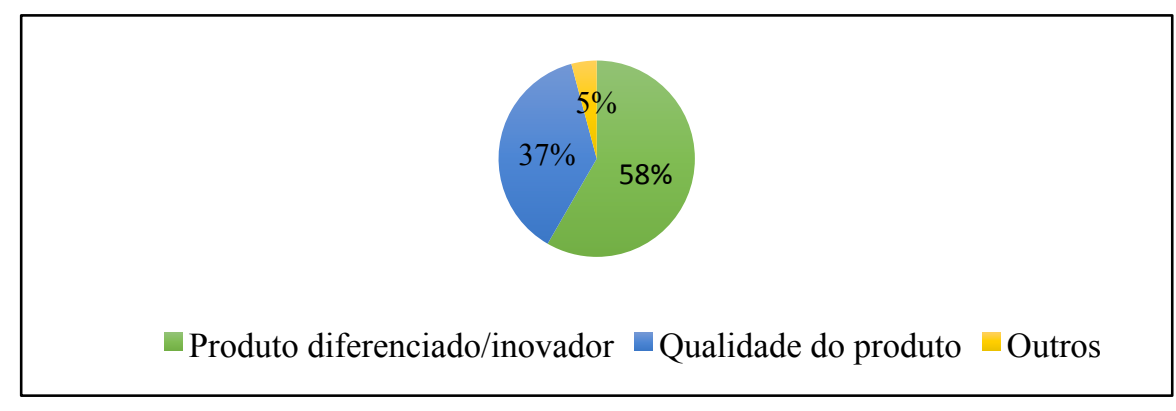

Fontes: Dados da pesquisa. 
Conforme os dados obtidos na pesquisa e ilustrados no Gráfico 1, o principal direcionador das empresas incubadas vinculadas à Rede Catarinense de Inovação, é a oferta de produtos diferenciados/inovador, contemplando $58 \%$ das empresas. A ligação deste dado com o objetivo da pesquisa, identificar os fatores associados à formação do preço de venda, gera um ponto refletivo, por se basear em componentes inéditos no mercado, dificulta a aplicação de parâmetros para avaliar o preço que os clientes estão dispostos a pagar pelo mesmo. Ponderando o gestor responsável pela decisão do preço de venda uma análise mais íntegra de seu produto para fins de aplicação de valor equivalente.

Atrelado ao fator-chave, o estudo identificou que em 91,66\% das empresas, a decisão pela formação do preço de venda é de responsabilidade do proprietário ou sócio-gerente, 4,17\% são os gestores não proprietários das empresas que decidem os preços de venda e 4,17\% das empresas tem uma área ou departamento de venda responsável por essa decisão. Os fatores que levam em consideração no momento da formação do preço de venda estão identificados no Gráfico 2.

Gráfico 2: Fatores considerados na formação do preço de venda

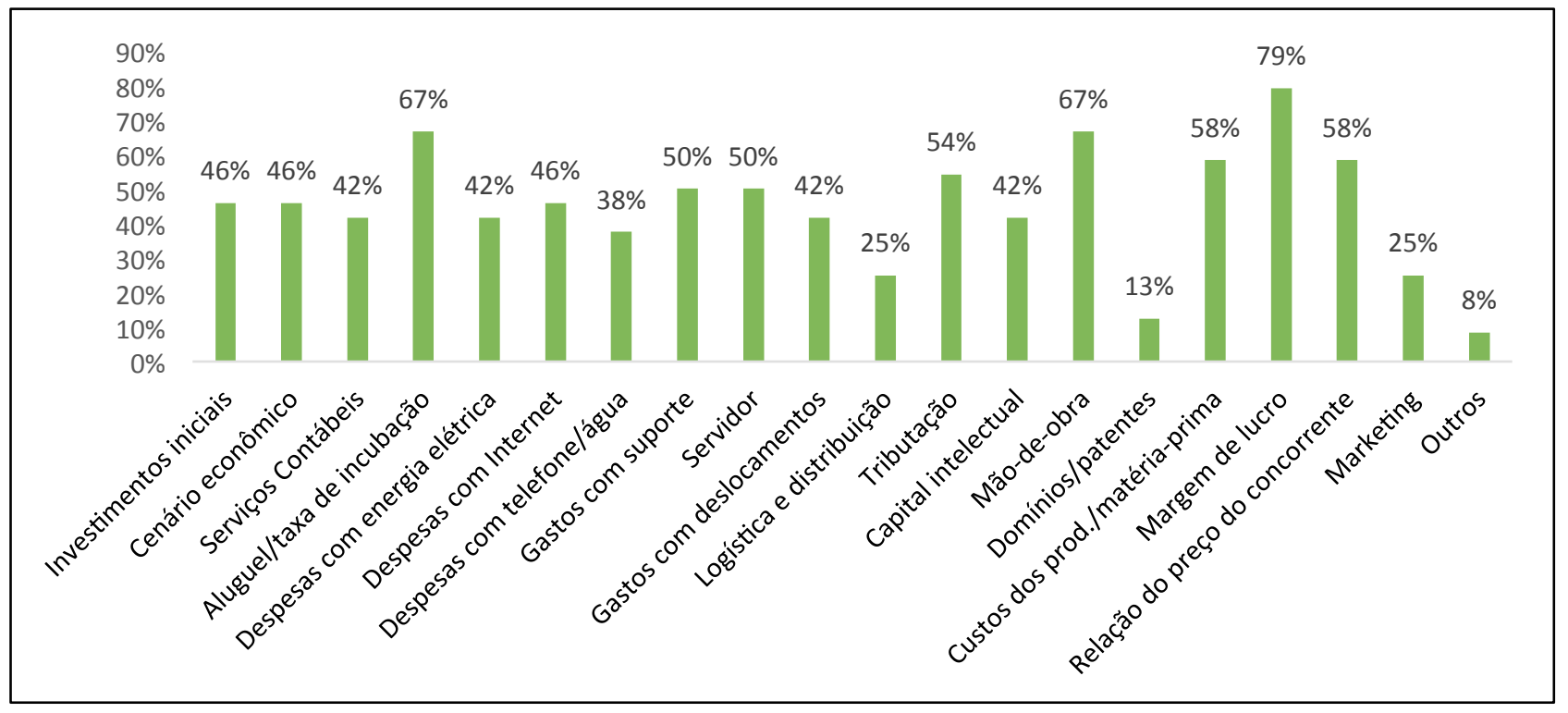

Fonte: Dados da pesquisa.

No que tange o objetivo deste trabalho, identificar os fatores associados na formação do preço de venda/serviço dos empreendedores incubados vinculados a RECEPETI, o Gráfico 2 contribui com elementos que viabilizam a explicação do atual estudo. Com base no Gráfico, os itens que a maioria das empresas aloca no preço final de seus produtos são: margem de lucro (79\%), mão-de-obra (67\%), aluguel/taxa de incubação (67\%), custo dos produtos/ matéria-prima (58\%), relação do preço do concorrente (58\%), tributação (54\%), gastos com suporte (50\%), servidor (50\%), entre outros.

Conforme destacado, a margem de lucro está alocada ao preço dos produtos/serviço em 79\% das empresas respondentes. Este fator é bastante típico de ser considerado nestas circunstâncias. Ao serem questionados sobre o percentual de margem de lucro considerado, $62,5 \%$ dos respondentes assinalaram praticar uma margem superior a $30 \%$. Este percentual elevado se caracteriza por ter uma representatividade na atividade de prestadores de serviços. Indo ao encontro ao dado de valores com domínio/patentes, os quais são incorporados ao preço 
final, somente em $13 \%$ das empresas, identifica a aplicação de valores em curto prazo, não destacando os investimentos em longo prazo.

Outro item mencionado pelos pesquisados foi o aluguel/taxa de incubação, com $67 \%$ das respostas. Por ser caracterizado como empresas incubadas, todos possuem estes dispêndios em suas despesas, conforme os dados evidenciados, são alocados ao produto final pela maioria das empresas.

Com índice de $67 \%$ dos respondentes, a mão-de-obra também está associada aos principais fatores alocados no preço final. Este dado, conforme já mencionado, também é característica de empresas prestadoras de serviços, como são a maioria da amostra deste estudo. Ligado a esta questão, foi questionado como ocorre o cálculo financeiro da mão-de-obra agregado ao produto. $80,80 \%$ responderam associar esse cálculo com base nas horas executadas no projeto, $30,8 \%$ assinalaram também utilizar bases dos preços utilizados pelos concorrentes/mercado, 26,9\% mencionaram avaliar de acordo com o nível do colaborador que irá executar e 7,7\% de acordo com a convenção coletiva da categoria.

Ainda por meio do Gráfico 2, identifica-se que os fatores ligados ao custo dos produtos e as matérias-primas são incorporados ao preço final dos produtos/serviços em $58 \%$ dos entrevistados. Em 50\% dos entrevistados assinalaram alocar ao preço final os gastos com suporte e servidor, refletindo esse dado, pois a amostra pertence ao setor de prestação de serviços, sendo necessário repassar ao preço final.

Outro ponto levantado na pesquisa decorre da atualização dos preços, sendo indagados quais fatores levam em consideração no momento de atualização dos preços de venda dos produtos/serviços ofertados. Sendo ilustrado o retorno no Gráfico 3.

Gráfico 3: Fatores considerados para atualização do preço de venda

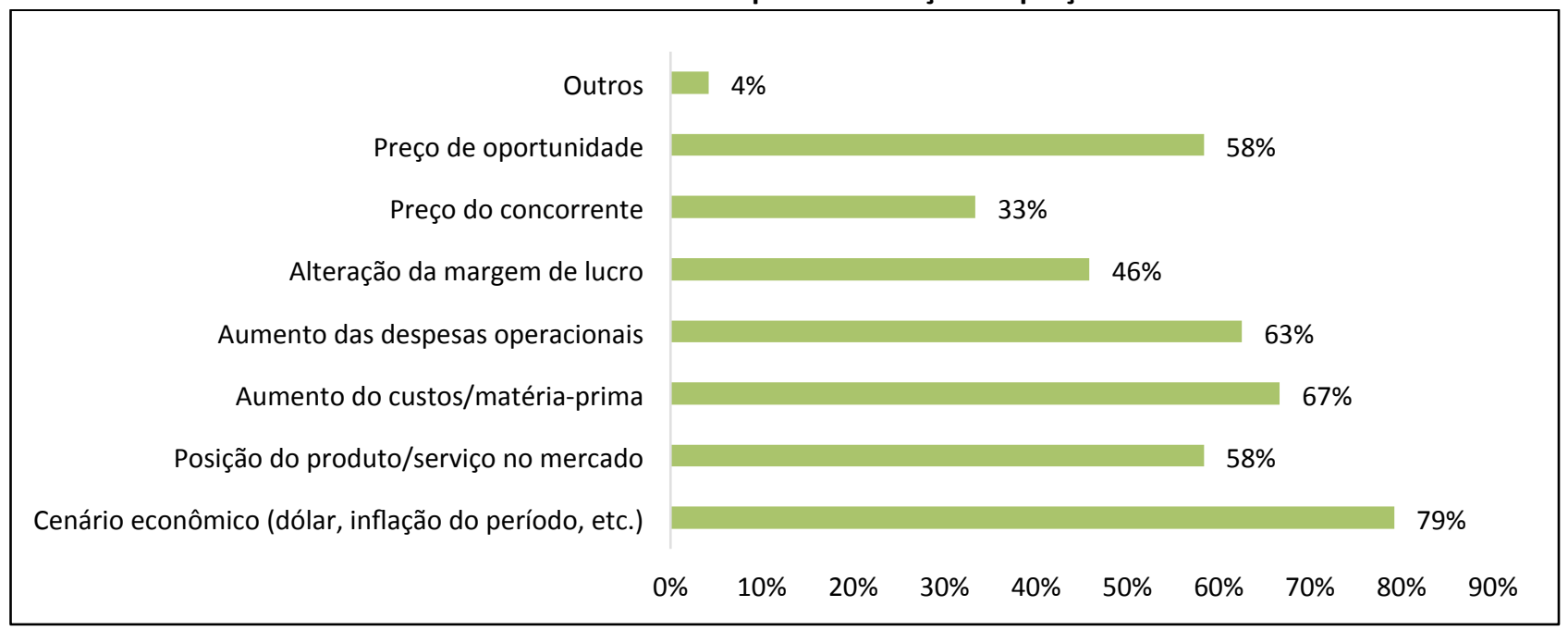

Fonte: Dados da pesquisa.

Por meio do Gráfico 3, verifica-se que os principais fatores associados na atualização dos preços de venda estão ligados ao cenário econômico e ao aumento dos custos e despesas das atividades ligadas ao produto final.

A pesquisa também buscou identificar se os empresários incubados vinculados utilizam algum método para a formação do preço de venda, conforme Gráfico 4. 
Gráfico 4: Métodos para a formação de preço

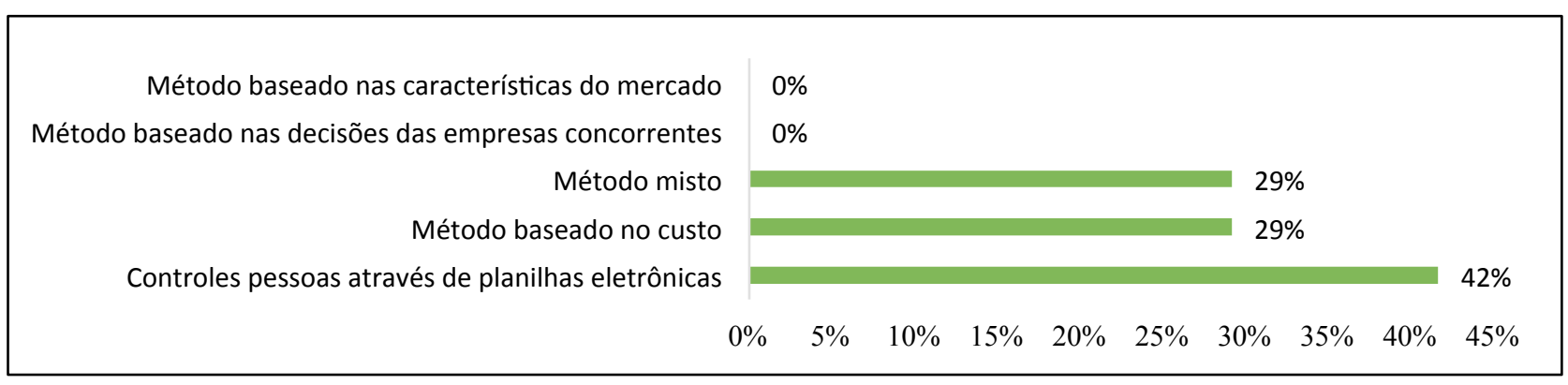

Fonte: Dados da pesquisa.

Percebe-se por meio da visualização do Gráfico 4, que os métodos utilizados pelos incubados para a formulação do preço de venda, refere-se a controles pessoais por meio de planilhas eletrônicas, correspondendo a $42 \%$ dos respondentes. 0 método baseado no custo, que conforme Santos (2012) é o mais comum na prática dos negócios, é utilizado por 29\% dos entrevistados. E outros $29 \%$ afirmam que utilizam o método misto, sendo este, segundo Santos (2012) o método mais aceitável/correto no mercado.

Na sequência questionou-se sobre a utilização de algum método para o controle dos custos. Dentre os respondentes, $50 \%$ afirmam que não utilizam nenhum método para o controle específico do custo dos produtos/serviços, dos quais, $66,68 \%$ mencionaram ser por meio de controles em planilhas eletrônicas, 8,33\% utilizam o método de custeio por absorção, 8,33\% empregam o custeio variável em suas atividades, $8,33 \%$ tem o custeio padrão e 8,33\% assinalaram utilizar outros meios para controlar os custos.

Com base nos achados levantados nesta pesquisa, para incorporar melhor a visão dos incubados em relação aos preços ofertados, a Tabela 1 identifica quão satisfeitos os empresários/clientes estão com o preço estabelecido e se supre as necessidades de cada produto/serviço. Sendo o peso 5 para muito satisfeito e peso 1 para insatisfeito.

Tabela 1: Nível de satisfação em relação ao preço ofertado

\begin{tabular}{|c|c|c|c|c|}
\hline \multicolumn{2}{|c|}{ Dados } & $\begin{array}{c}\text { O preço estabelecido } \\
\text { condiz com as necessidades }\end{array}$ & $\begin{array}{l}\text { Está satisfeito com o preço } \\
\text { estabelecido do(s) seu(s) }\end{array}$ & $\begin{array}{l}\text { O preço estabelecido tem } \\
\text { boa aceitação pelos seus }\end{array}$ \\
\hline \multirow{5}{*}{ 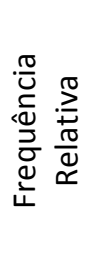 } & Peso 1 & $0 \%$ & $0 \%$ & $4,2 \%$ \\
\hline & Peso 2 & $0 \%$ & $4,2 \%$ & $8,3 \%$ \\
\hline & Peso 3 & $20,8 \%$ & $29,2 \%$ & $41,7 \%$ \\
\hline & Peso 4 & $37,5 \%$ & $37,5 \%$ & $25,0 \%$ \\
\hline & Peso 5 & $41,7 \%$ & $29,1 \%$ & $20,8 \%$ \\
\hline \multicolumn{2}{|c|}{ Média dos pesos } & 4,2 & 3,9 & 3,5 \\
\hline \multicolumn{2}{|c|}{ Desvio padrão } & 0,78 & 0,88 & 1,06 \\
\hline
\end{tabular}

Fonte: Dados da pesquisa.

Relativo ao preço estabelecido ser condizente com as necessidades dos produtos/serviços, por meio da Tabela 1, visualiza-se que 41,7\% consideram peso máximo para essa afirmativa, ou seja, de acordo com as respostas, o preço estabelecido está adequado conforme as necessidades dos empresários. Para esta questão a média estabelecida foi de 4,2 e 
um desvio padrão de 0,78 , identificando satisfação por parte dos respondentes em relação aos preços estabelecidos.

Analisando o nível de satisfação dos empresários com o valor ofertado pelos seus produtos/serviços identificado na Tabela 1, depara-se com uma média de 3,9 e desvio padrão de 0,88 , não sendo dados que estimam alta aceitação, portando o preço estabelecido não é o real anseio dos empresários. Porém, é possível constatar que 29,1\% dos entrevistados, atribuíram peso máximo para esta questão, sendo assim, apesar de não ser o melhor resultado considerável para esta questão, observa-se uma quantidade notória de entrevistados que está satisfeita com o valor ofertado de seus produtos/serviços.

Em relação a aceitação dos clientes das empresas incubadas com o preço ofertado, conforme identificado na Tabela 1, do ponte de vista dos empresários, seus clientes não estão muito satisfeitos com os valores de seus produtos. Esses dados são constatados, pois mais de $50 \%$ dos respondentes atribuíram peso entre 1 a 3, evidenciando a pouca satisfação. A média foi de 3,5 e o desvio padrão de 1,06 , sendo a questão que teve dados mais dispersos entre os pesquisados.

Por fim, a pesquisa solicitava para que o respondente mencionasse quais são as principais dificuldades para a formação do preço de venda de seus produtos/serviços, destacando-se:

- Estimar/conhecer o custo real de cada produto/serviço;

- Repassar o valor apropriado para o cliente final;

- Repassar a atualização dos preços com base do cenário econômico e dos ajustes decorrentes;

- Saber o ponto de equilíbrio: Custo x Lucro;

- Falta de experiência no mercado.

Estas situações são apontadas como dificuldades sentidas pelos empresários no momento de formular o preço final dos seus produtos/serviços. Visualizando assim, o grande impasse que os empresários têm neste momento, principalmente por se tratar de empresas prestadoras de serviços ligados à atividade de software. De modo geral, empresas deste porte encontram dificuldades para comparação de preços com outras empresas atuantes no mercado, por ser na maioria produtos inovadores, e também pela dificuldade de calcular o real preço de cada fator envolvido na prestação de serviço.

Outro fator relevantes para ser levantado por meio dos dados desta pesquisa, é o fato da maioria das empresas envolvidas serem iniciantes na atuação do mercado, assim ainda não possuem a maturidade empresarial de longo prazo. De fato o caminho para essas empresas é longo para a designação efetiva do seu preço real para repassar aos seus clientes, mas de acordo com essa pesquisa, há interesse para esse fato por parte dos pesquisados, podendo assim caracterizar como um ponto positivo e de satisfação para os objetivos traçados desta pesquisa.

Cabe ressaltar que o curto ciclo de vida dos pesquisados (população/amostra) ocorre por serem empresas em incubação, as quais permanecem nas redes por um tempo aproximado de até 5 anos, desejando-se quer as mesmas despontem no mercado com vida própria. 


\section{CONCLUSÃO}

O artigo visou responder questão de estudo relacionada aos principais fatores associados para a formação do preço de venda/serviço dos empreendedores incubados na RECEPETI (Rede Catarinense de Inovação). Com esse propósito objetivava identificar os fatores associados para a formação do preço de venda/serviço dos empreendedores incubados vinculados a RECEPETI.

Nessa direção, os autores entendem que a pergunta de pesquisa foi convenientemente respondida de vez que foram identificados, por meio das respostas obtidas por intermédio da aplicação de questionários aos gestores das incubadas, os fatores associados à formação do preço de venda, bem como a forma da atualização dos mesmos. Em razão disso, o objetivo priorizado também foi atingido, ou seja, foram levantados os principais fatores ligados à formação do preço de venda dos produtos/serviços ofertados.

Além disso, com base no levantamento de dados efetuado foram reputadas às duas hipóteses anteriormente levantadas. A primeira aventava a possibilidade de os gestores desse tipo/porte de empreendimento priorizarem exclusivamente o controle dos aspectos operacionais para a formação do preço de venda. A segunda cogitava acerca de se englobar todos os referidos custos decorrentes para a constituição do preço final dos produtos/serviços ofertados. Como visto, a maioria dos administradores utilizava, mesmo que parcialmente, métodos apropriados para a formulação do preço, porém não estão cientes se há o repasse total dos custos para o preço do produto ou serviço.

Quanto aos resultados mais importantes, os principais fatores que a maioria das empresas alocam no preço final de seus produtos são: margem de lucro (79\%), mão-de-obra (67\%), aluguel/taxa de incubação (67\%), custo dos produtos/ matéria-prima (58\%), relação do preço do concorrente (58\%), tributação (54\%), gastos com suporte $(50 \%)$, servidor (50\%). Em casos de atualização do preço de venda, os principais fatores associados na atualização dos preços de venda estão lidados ao cenário econômico e o aumento dos custos e despesas das atividades ligadas ao produto final.

No que concerne às limitações associáveis ao estudo, convém destacar especialmente os aspectos relacionados ao pequeno número de participantes, em virtude do exposto, não cabe generalizar os achados desta pesquisa.

Como recomendação para trabalhos futuros, sugere-se a expansão da abrangência para as demais incubadoras sediadas nos demais estados brasileiros. Ainda, seria interessante investigar os métodos associados na estimação do custo real de cada produto utilizados por esse tipo/porte de empreendimento.

\section{REFERÊNCIAS}

Adegbite, O. (2001). Business incubators and small enterprise development: the Nigerian experience. Small Business Economics, 17 (3), 157-166.

ANPROTEC - Associação Nacional de Entidades Promotoras de Empreendimentos Inovadores. (2011). Incubadoras e Parques. Disponível em: <http://www.anprotec.org.br>. Acesso em: 07 fev. 2016.

Aranha, J. A. (2000). Incubadoras de empresas. In: FILION, Louis Jaques; DOLABELA, Fernando. 
Boa idéia! E agora? São Paulo: Cultura Editores Associados, cap. 17.

Assef, R. (2005). Gerência de preços: como ferramenta de marketing. 2. ed. rev. e atual. Rio de Janeiro: Elsevier.

Braga, D. P. G., Braga, A. X. V., \& Souza, M. A. (2010). Gestão de custos, preços e resultados: um estudo em indústrias conserveiros do Rio Grande do Sul. Contabilidade, Gestão $e$ Governança, 13 (2), 20-35.

Bodnar, G. H, \& Hopwood, W. S. (1990). Accounting Information Systems (4a ed.). Massachusetts: Allyn and Bacon.

Brasil. (2002). Ministério da Ciência e Tecnologia. Livro branco: ciência, tecnologia e inovação. Brasília: Ministério da Ciência e Tecnologia.

Bruni, A. L., \& Famá, R. (2012). Gestão de custos e formação de preços: com aplicações na calculadora HP 12C e Excel. 6. ed. São Paulo: Atlas.

Callado, A. L. C., Miranda, L. C., \& Callado, A. A. C. (2003). Fatores associados à gestão de custos: um estudo nas micro e pequenas empresas do setor de confeç̧ões. Revista Produção, 13 (1), 64-75.

Dornelas, J. C. A. (2002). Planejando incubadoras de empresas: como desenvolver um plano de negócios para incubadoras. Rio de Janeiro: Campus.

D’Afonsêca, L. A. G. G. (2007). O perfil e o comportamento estratégico dos empreendedores de empresas incubadas em Salvador. (104 f). Dissertação (Mestrado em Administração) Programa de Pós-Graduação em Administração Estratégica da Universidade de Salvador UNIFACS, Salvador.

Gil, A. C. (2008). Como elaborar projetos de pesquisa. (4⿳亠口冋口 ed.). São Paulo: Atlas.

Lalkaka, R. (2002). Technology business incubator to assist a innovation based economy. Journal of Change Management, 3 (2), 167-176.

Lopes, J. E. de G. (2006). O fazer do trabalho científico em ciências sociais aplicadas. (1a ed.). Recife: Editora Universitária.

Nagle, T. T., \& Hogan, J. E. (2007). Estratégia e táticas de preço: um guia para crescer com lucratividade. 4. ed. São Paulo: Pearson Education do Brasil.

Padoveze, C. L. (Org.). (2012). Orçamento empresarial. São Paulo: Pearson Education do Brasil. \& Vasconcelos, Y. L. (2012). Contabilidade. Curitiba: IESDE Brasil S.A.

Porter, M. E. (2002). A nova era da estratégia. In C. A. Júlio \& J. S. Neto (Orgs.). Estratégia e Planejamento. São Paulo: Publifolha.

RECEPETi - Rede Catarinense Inovação. Histórico. Disponível em: <http://recepeti.org.br/institucional/historico/>. Acesso em: 05 fev. 2016.

Santos, J. J. dos. (2005). Fundamentos de custos para formação do preço e do lucro. (5a ed.). rev. ampl. e mod. São Paulo: Atlas.

Sartori, E. (2004). Gestão de preços: estratégia e flexibilização de preços, fidelização de clientes e aumento de rentabilidade. São Paulo: Atlas.

Souza, L. A., Dantas, P. F., Aouar, W. A., \& Barreto, L. K. S. Modelo de gestão em incubadoras e mapas de desempenho. Revista Ciências Administrativas, 1 (1), 112-130. 
Sveiby, K. E. (1998). A nova riqueza das organizações. Rio de Janeiro: Campus.

Teixeira, M. L. M., \& Mazzon, J. A. (2000). Orientação ética quanto à mudança social envolvendo stakeholders. Revista de Administração Mackenzie, 1 (1), 51-65.

Turato, E. R. (2003). Tratado da metodologia da pesquisa clínico-qualitativa: construção teóricoepistemológica, discussão comparada e aplicação nas áreas da saúde e humanas. (2a ed.). Petrópolis: Vozes.

Zornig, F. (2007). Acerte o preço e aumente seus lucros. São Paulo: Nobel.

Wernke, R., \& Lembeck, M. (2012). Método UEP como facilitador da aplicação do CPC-16Estoques pela contabilidade de custos: estudo de caso. In: Congresso Brasileiro de Custos, 19a , 2012, Bento Gonçalves. Anais... Bento Gonçalves. 